\title{
Practice guidelines that may kill
}

\author{
Lodovico Balducci
}

Received: 15 January 2014/ Accepted: 16 January 2014/Published online: 13 February 2014

(C) Springer-Verlag Italia 2014

The mission of our Journal and our movement is to privilege the patient over the disease. We hold that the patient represents the ever changing reality facing the provider. The disease is a theoretical construction that allows the provider to categorize and approach different illnesses [1] in the ever changing patient landscape. To pursue our mission, we face an uphill battle as we defy the trend of a time enamored with technology. This "high tech, low touch" society aims to bypass the pain of the human interactions, to ignore the discomfort of confronting a mystery in every human encounter. We do hold that life is a mystery in its original sense. The Latin Mysterium indicated a rite that allowed humankind to achieve an immediate (without mediators) experience of the deity, that is of the reality in its entirety. By saying that human life is a mystery we state that it is a living reality, self-evident, that cannot be circumscribed by words, cannot be conceptualized but only can be lived. The hallmark of this living experience is a kaleidoscope of sentiments moving and interacting on a background of intertwined joy and suffering. That includes the pain of growing, of delivering a continuously renewed human being and the joy that follows a parturition and any other difficult accomplishment.

Human cloning is perhaps the ultimate aspiration and ambition of a "High Tech" culture. With human cloning, the high tech society hopes to eliminate suffering by creating the healthiest, most handsome, most intelligent and most successful human beings in the delusion that these produces of technology may defeat disappointments, diseases, and death, that thanks to genetic manipulations human growth may be made painless. Has anybody ever

L. Balducci $(\bowtie)$

Moffitt Cancer Center, Tampa, FL, USA

e-mail: lodovico.balducci@moffitt.org mentioned to clone Jesus Christ, or Francis of Assisi, or Luther, or Gandhi, or any world leader who has offered to carry other people's pain, as "a lamb led to the slaughter", to offer his/her suffering or death for the salvation of many? High tech society's final hope is to dispense with sacrifice, that is to dispose of love. Sacrifice means to make oneself "sacred" that is reserved to the service of another person. As such it is the basic ingredient of love. Human cloning may represent a fictional manifestation of an all too real goal: to eliminate the disconcert of dealing with the individual mystery of each person, of facing a reality that cannot be predicted by a mathematical model and crystallized on a computer screen. Nowadays both patient and physician share this aspiration and the result is a very expensive medical practice in which $99 \%$ of the time is spent in obtaining imaging and laboratory tests.

In this issue of JMP Ricci and collaborators denounce the lack of reliability of an instrument enshrined in modern medical practice: the practice guidelines [2,3]. The authors review the guidelines issued by different organizations toward the management of the same disease and reveal their inconsistency. In most cases, they also reveal the absence of any scientific evidence in support of these guidelines. This is a type of study that we would like to report more often in our journal, because it is germane to our mission. In general, we would like for more authors to ask to what extent medical technology is at the service of the person, or has assumed a life on its own that may work against the person.

Few years ago in Asunción, I attended a meeting of the Sociedad Sur Americana de Medicina Interna. A Brazilian epidemiologist described very effectively the scourge of cervical cancer that is the number one killer of women in developing countries. She emphasized several prevention modalities that included vaccination against HPV, 
protected intercourse, and early detection. Surprisingly, she did not even mention sexual abstinence and monogamy, that are beyond doubt the most effective forms of prevention of sexually transmitted disease. Cervical cancer and other HPV-related cancers (penile cancer, oral cancer, anal cancer in homosexuals) are fully preventable by changes in human behavior, but our scientists prefer to trust prevention to an expensive and cumbersome technology of unproven effectiveness! Few years ago, an unarmed Brazilian electrician, immigrant to the UK was killed by the London police that followed literally the guidelines to deal with suspected terrorists! Guidelines divorced from the person may destroy the person.

Of course Ricci et al. do not imply that all guidelines should be discarded, simply that they should not be allowed to assume a life on their own, independent from the person. This is a good time to see which guidelines are at the service of the person and which ones may be our enemies.

First of all, it is useful to examine the reason to have guidelines. Since ancient times practitioners were looking for a track that helped them to find a way to exit the maze of the disease. The Hippocratic oath itself, with its dos and don'ts may be constructed as a guideline of physician behavior. The biblical injunction that lepers announce their arrival in the street was a guideline to prevent the spreading of the contagion.

In our times guidelines have essentially two important roles in the service of the person: to assure that third party payers do not deny essential medical interventions, and to assist the practitioners in conditions of uncertainty. A third important role of the guidelines is support of epidemiological research. By assuring that all patients with stage II breast cancer receive some form of adjuvant chemotherapy or that all patients with moderate hypertension or increased cholesterol receive the same form of treatment they may allow to study the long-term benefits and complication of these approaches in the general population. The efficacy of these approaches has been demonstrated in rigorous randomized clinical trials, but their effectiveness, that is their benefits in a population that is highly diverse and cannot be included in clinical trials can only be assessed in epidemiological studies [4].

Ideally guidelines should be based on the best evidence, that is on randomized clinical trials. When this evidence is absent one has to recur to retrospective analysis, which quite often are unreliable or to the so-called "expert opinion" that are even less reliable. The expert opinion may be flawed by personal interest. For example, the recommendation that man 50 and older be screened for prostate cancer issued more than 20 years ago by the American Urological Association, and recently retracted, represented a profit windfall for the members of that association; thanks to the guidelines they could perform twice as many prostatectomy as in the past. Sometimes it would be wiser for the guidelines to state that there is no evidence to support a recommendation and that more clinical trials should be conducted.

In discussing guidelines it is important to distinguish prevention and treatment guidelines. The prevention guidelines are generally the most controversial as they involve a large population for the benefits of a few. For example, the recommendation to screen men for prostate cancer did not reduce the mortality of these individuals, but increased dramatically the complications of a treatment (sexual impotence, incontinence, fatigue, diabetes, and occasional death, and bankruptcy) that in the majority of cases proved to be detrimental [5]. Recently, the guidelines to transfuse hemoglobin of $10 \mathrm{GM} / \mathrm{dl}$ to patients with stable coronary artery disease have been retracted because the evidence of benefits was unclear and the risk of the transfusions well established [6]. In the United States the only reliable source of prevention guidelines are those issued by the United States Preventive Service Task Forces (USPSTF) a nonprofit organization that reviews periodically the evidence on which guidelines are based [7].

The issues may be different in treatment guidelines, as we are dealing with a smaller population of patients with a vested interest in a treatment that may save their life. No reasonable person would recommend a randomized controlled study of appendectomy versus sham operation in the case of acute appendicitis, because there is no direct evidence of the benefits of appendectomy. Yet, even when dealing with treatment guidelines it is important to reexamine practices that may appear innocuous and may turn out to be detrimental to the patients. A sobering call came from a randomized controlled study demonstrating that a policy of blood transfusions ad lib was associated with an increased mortality in the intensive care units when compared with a policy that restricted blood transfusions [8].

Guidelines are here to stay, and they are aimed to protect the patients from the avarice of third party payers or the vagaries of individual practitioners, but they may be lethal when they are applied indiscriminately irrespective of the patient to whom they are applied. It is clear that discovery of a breast nodule in a 95-year-old demented woman would not improve her survival and may be associated with anguish and severe treatment complications; it is clear that lowering the blood pressure or the cholesterol of a mild hypertensive patients with metastatic colon cancer will only increase the suffering of that patient, unless the patient is at risk of a stroke or a heart attack that may kill him/her prior to the cancer.

We should all thank Ricci et al. for their study that denounces the unreliability and the inconsistencies of treatment guidelines. To assure that the guidelines are at the service of the person we should always ask on what 
kind of evidence are they based and whether they will be beneficial to the individual patient.

\section{References}

1. Tyrer P (2013) Nosology is usually wrong, but is a test bed for science: a commentary on Markon. J Pers Disord 27:590-593

2. Massoni F, Ricci P, Ricci S (2014) Does the patient or pathology exist? J Med Pers (in this issue). doi:10.1007/s12682-014-0165-6

3. Reames BN, Krell RW, Ponto SN et al (2013) Critical evaluation for oncology clinical practice guidelines. J Clin Oncol $31: 2563-2568$
4. Krasny-Pacini A, Chevignard M, Evans J (2014) Goal management training for rehabilitation of executive function: a systematic review of effectiveness in patients with traumatic brain injury. Disabl Rehabil 32:105-116

5. Schroder FH, Hugosson J, Roobot MJ et al (2012) Prostate cancer mortality at 11 year follow up. N Engl J Med 366:981-990

6. Kansagara D, Dyer E, Englander H et al (2013) Treatment of anemia in patients with heart disease: a systematic review. Ann Intern Med 159:746-757

7. Agency for Health Care Research and Quality: Guide to Clinical Preventive Services 2012

8. Vincent JL, Baron JF, Reinhart K et al (2002) Anemia and blood transfusions in critically ill patients. JAMA 288:1499-1507 